\title{
Ancient Diseases: New Cures
}

\section{Hague A*}

CellSonic: Manufacturers of Medical Equipment, United Kingdom

*Corresponding author: Andrew Hague, President, CellSonic: Manufacturers of Medical Equipment, United Kingdom, Tel: +1 315210 6307; Email: cellsonic.beauty@gmail.com

\section{Short Communication}

It is said that you should never get between a hippopotamus and water. The same applies to me and my bicycle. I have cycled for 67 years and shall never stop; something has to carry me to the pearly gates.

Occasionally I ride with a group of people a bit younger than me. One of the men asked me if I take any medicines. Funny question because I never get ill.

"No", I said, "Unless you include toothpaste twice a day". He thought I was daft and swallowed some pills which he said were for his diabetes. I later learned he had suffered a stroke and had a titanium knee joint. In desperation he had started cycling a few years ago and it has built his strength up to the level where I doubt he needs medication but he thinks he does. The bicycle is my medicine [1].

I am a tourist, not a racing cyclist. Racing is extreme and stressful. Without reference to recorded statistics and just from observation, the tourists outlive the racers by ten to twenty years and for sure we beat the normal, idle, car dwellers. Pottering along with time to appreciate the countryside and hear the birds is enjoying life, as beneficial as strengthening muscles, heart and lungs.

An Indian friend speaks highly of meditation. That seemed too much for my down to earth approach until I learned what it involved. I had probably been meditating for all those 67 years spent cycling. The body works best when the mind is relaxed and the mind relaxes when the body is working. I never knew any different. Only now that illness has become a business matter do I realise that my experience is not normal. Most people are ill because their lifestyle makes them ill.
Ayurvedic medicine [2], much respected in India, is more about avoiding illness than curing illness although it does offer cures. Unknown to me, I and all my cycle touring friends had been practicing Ayurvedic medicine for years. It was to us the obvious way to live. We didn't smoke because we saw how the smokers couldn't ride up hills. We didn't over eat although we ate more than anyone else. That was due to burning more calories than the sedentary. We measured food by miles. A jam and cheese sandwich was ten times more than an apple. No one ever got fat.

In most governments, the health of the people is the responsibility of the Minister for Health or so it is said. In fact, the Minister is responsible for a spending budget, often greater than the defense budget, for the running of hospitals, doctors' clinics and medical schools. The minister having most influence on health is the Minister for Transport. If only they realized what they are doing. They worship anything on four wheels or more. Cars are demons with a right to speed, be taxed and pollute. The more there are, the fewer people will ride to work for fear of being knocked down. This keeps the Minister for Health busy. Cycling is the answer to many of the world's problems. Many people know this and keep it secret from politicians.

All cyclists in developed countries accept being thought of as eccentrics. They inwardly know that they have benefits the idle don't have so the smirks and rude comments don't stick. In developing countries, cyclists would love to own a car. Get prosperous my friends but keep cycling. That bit you have got right and you will always have the fastest vehicle in town [3].

The idle collect disease. It is either own grown or lands in them and they are unable to throw it out. The diseases 


\section{Ergonomics International Journal}

cultivated by sloth are diabetes type 2, clogged hearts and decaying bones. Infections of many types become too much for the immune system in a weak body. Anti-biotic aid recovery until resistance to the anti-biotics builds up to be ineffective. I heard the comment recently that no one taking aspirin is doing so because they have an aspirin deficiency. The real worry is the increase of cancer. How much is allowed by ineffective immune systems and how much caused by modern pollutants?

The goal of a cycling, vegetable eating population is unrealistic as ideals always are. Therefore, some medical repair is needed. For a hundred years or more, pharmaceuticals have made their contribution. Plumbers have done better bringing drinking water and sanitation to the masses whilst medical drugs have played their part. The limit to what can come from laboratories seems close. Still they never got a cure for diabetes, cancer and the brain diseases such as Alzheimer's and Parkinson's.

Those gaps are being filled by CellSonic [4]. The rules are clear: no side effects on the patients or the therapist. Drugs and surgery always have side effects. They are also expensive. CellSonic has the lowest cost of cure, a cost that is never calculated probably because there seldom was a cure until CellSonic came along [5].

Allow for the unfortunate illness and let it be stopped by a method as close to natural as possible. If natural means the same as the body would do to itself then that is how CellSonic has to work and it does. The easy one is stopping cancer [6]. Too easy the marketing experts will say because everyone expects a difficult disease to be difficult to cure. Cancer is only difficult if you are trying to stop it with the wrong tools. It is not a bio-chemical disease so pharmaceuticals are useless as we see every day. Their only success is when a patient survives severe poisoning. We all know the difference between torture and medicine and chemotherapy is not medicine whatever your doctor lies to you. Cancer is an electrical fault so the cure is to switch the polarity of the cells. This has been done for many years by internal electroporation but it is tricky. Now CellSonic does it non-surgically and irreversibly. It takes a few minutes, requires little skill, has no side effects and is low cost [7].

An example of a trickier task for CellSonic is gangrene [8]. Ask any doctor about gangrene and they will tell you the limb has to be amputated. That's what they were taught and they never found an anti-biotic to eradicate the infection and promote new tissue growth. Now zap with CellSonic. It kills the infection mechanically without knowing what the infection is and causes new nerves and tissue to grow.
Severed spinal cord is considered impossible to heal. It is difficult even for CellSonic but only because it takes time. The treatment is easy. Aim pulses the full length of the spine, across the hips and down both legs to the ankles. Gradually the nerves either join up again or form a new network, probably both, until the brain can send instructions to withering muscles and they too will slowly come back to life. Reports on a few cases have come in with success on patients following traffic crashes. No drugs are used. No pain is caused. It takes time and the patients enjoy the treatments. This is good medicine [9].

The means by which CellSonic does this is using very intense pressure pulses so the affix VIPP is now used to describe the science. It is a unique method deploying fast switching of a high voltage across a gap between anode and cathode creating an acoustic pressure pulse the same as thunder in the sky caused by lightning. The combination of the pressure and electrical field of extremely short duration appears to be the secret of the success [10].

Brain cancer tumours have been treated and no damage to the brain reported. This leads us to hope that brain disease can be cured by stimulating tissue growth and doctors in different continents are trying it on patients with, so far, signs of success.

Natural medicine relies on harmless potions and selfconfidence by the patient. In many cases that is no more than cycling and enjoying a good night's sleep. When the disease is more intransigent it needs the CellSonic VIPP pulse to kick it into a changed state, to reverse the polarity of cancer or bring the Islets Langerhans on the pancreas back to life so that they recommence producing insulin. This is where CellSonic comes in because with pharmaceuticals there is no hope. The good news is that CellSonic is as close to natural medicine as can be.

Two pieces of information that will grow into an understanding as feedback increases are about happiness and teeth.

Often a conversation with a CellSonic doctor ends in them telling me how much the patient enjoyed the treatment. At first I put this down to them liking the doctor and the fact that they were saving money compared to some quack trying to inflict injury with a scalpel but with these comments coming in regularly I realized that there is an effect taking place. Be it the lady with gangrene, the man with a severed spinal cord or the woman with lower back pain, I knew that we had a cause 


\section{Ergonomics International Journal}

and effect. Whether this is a cure for depression is too early to say.

The observation about teeth is interesting. At first, I saw no connection between dental decay and problems elsewhere in the body [11]. There was one lady patient who lectured me on the problems and insisted that CellSonic is the only cure. I am the spider in the middle of the web collecting and trying to make sense of the stories so I listen and wonder. If it goes wrong, it is my money and reputation on the line. I didn't want the few teeth she had left to fall out. She persevered and scared a few doctors until she found one who let her treats herself and she blasted away at her jaw aiming through the cheeks. She was well pleased with the result. I did not understand. Her aches and pains over the rest of her body had eased. This was too little evidence to claim as a medical procedure. Then from a different sector to which I had not mentioned this case came a similar story that through the teeth run circuits of electrical meridians. An infection in the tooth (periodontal disease) can be cured by CellSonic and this also cures arthritis in the wrist. Aim at the tooth to cure the wrist. If that seems strange to you it does to me so I stay open minded and by passing this information to you I may receive further comment and steadily we learn. The idea is along the lines of Chinese medicine. What we contribute is a powerful, manageable and totally safe technology that kicks the body into a positive response that the brain likes. This is a new branch of medicine, CellSonic VIPP.

\section{References}

1. Andrew Hague, Dip M (2018) The Exercise Continuum and the Role of Doctors. OAJ Gerontol \& Geriatric Med 3(5): OAJGGM.MS.ID.555621.

2. Ayurvedic Medicine.

3. https://www.youtube.com/watch?v=KTT7i3SKpMQ

4. http://www.cellsonic-medical.com/

5. http://www.cellsonic-medical.com/about.htm

6. Hague A (2018) Cancer's Change of Direction. J Med Res Biol Stud 1: 104.

7. Hague A (2017) Review of reports of curing cancer with CellSonic VIPP machines. Gen Med Open.

8. Hague A (2018) Dro purshottam bagul case summary. Gen Med Open.

9. Hague A (2018) Spinal cord injury patient treated with cell-based therapy and CellSonic VIPP. Gen Med Open.

10. Hague A (2018) Doctors Should Be Paid More. International Journal of Research Studies in Medical and Health Sciences 3(6): 5-9.

11. Hague A (2017) Periodontal Disease. Nov Tech Arthritis Bone Res 2(2): 555582. 